\title{
Wasīlatu Adobe Flash Wa Faāliyatu Istikhdāmī hā Litarqiyah Qudratu At- țullābi ‘ala Al- Mufradat
}

\author{
Mar'atus Sholehah $^{1}$ \\ ${ }^{1}$ Institut Agama Islam Negeri Langsa \\ 1 solehah026@gmail.com
}

\begin{abstract}
Abstrak
Mufradat adalah salah satu unsur bahasa yang paling penting yang harus dikuasi oleh setiap pelajar bahasa asing untuk meningkatkan kemahiran dalam berkomunikasi. Peneliti melihat bahwa banyak dari guru masih menggunakan media pembelajaran yang lama yaitu media buku dan papan tulis saja dalam kegiatan belajar bahasa arab, dan media ini belum mendorong siswa dalam pembelajaran bahasa arab khususnya mufradat, dan mereka mengalami masalah seperti bosan, mengantuk, dan lain-lain. Dan untuk mengatasi masalah tersebut dengan menggunakan media adobe flash untuk meningkatkan kemampuan siswa dalam mufradat. Pendekatan yang yang digunakan dalam penelitian ini adalah penelitian eksperimen. Populasi dan sampel dalam penelitian ini adalah siswa kelas delapan di MTs Swasta Geudubang Aceh. Instrument yang digunakan dalam pengumpulan data adalah test. Hasil penelitian kemampuan siswa dalam pembelajaran mufradat adalah baik sekali, dan penggunaan media adobe flash untuk meningkatkan kemampuan siswa dalam mufradat efektif.
\end{abstract}

Kata Kunci: Media Adobe Flash , pembelajaran Mufradat 


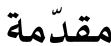

تعليم اللغة العربية هي محاولة المعلم في تفاعل تعلم اللغة العربية حتى الطلاب

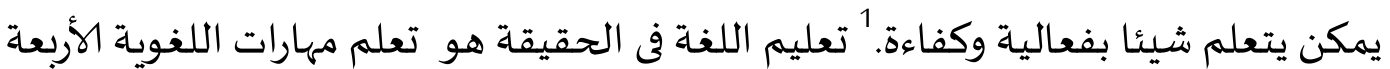

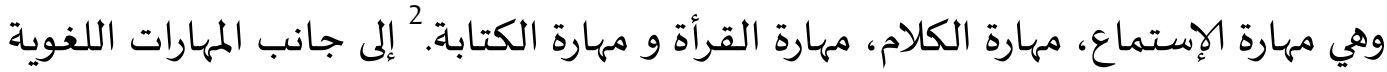

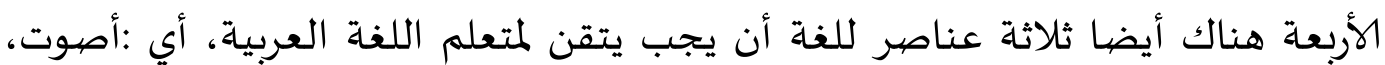
والمفردات، وتركيب. حتى الطلاب فهم اللغة إما من السمع، الكتابة أو الشفهي. وتحقيق الأهداف التعليمية المحدددة. 3

نظرا لأهمية المفردات في تعليم اللغة العربية، فيجب أن يكون المعلم طريقة،

Adobe واستراتيجية و وسئل تعليم جيد. وبالنظر إلى المشاكل يريد الباحثة تقديم وسيلة Flash في تعليم المفردات، مع وسيلة Adobe Flash تعلم المفردات سوف تصبح أكثر وضوحًا، مثيرة وغير مملة لأن Adobe Flash معبأة بالصيوت، فيديو، سِينمَائي، وبذلك تصبح عملية تعلم اللغة العربية أكثر ممتعة.

في ملاحظة الباحثة ، في MTs Swasta Geudubang aceh هناك أنواع المشاكل بما في ذلك، صعوبات الطلاب في فهم الكتاب الدرس العربية، أحد الأسباهها أن الدروس العربية دائما تعتبر صعوبة ومملة. بحيث لا يهتم الطلاب بدروس اللغة العربية وهذا يؤثر على إتقان مفردات الطلاب واحد اسبابها هو اقل وسيلة في عملية التعلم من اللغة العربية، حتى

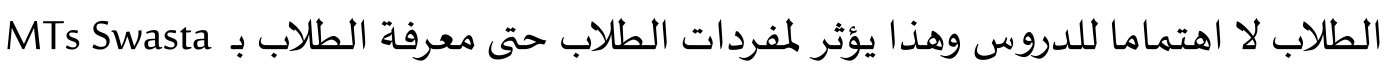
Geudubang Aceh "وسيلة adobe flash وفعالية استحدامها لترقية قدرة الطلاب على المفردات بـ MTs

Swasta Geudubang Aceh

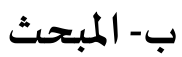

${ }^{1}$ Moh. Edi Komara, Penerapan Metode Pembelajaran Bahasa Arab, Journal Of Arabic And Litenature, Vol 1, No. 2, 2017, hlm. 41.

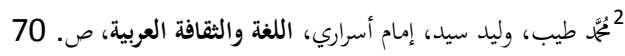

${ }^{3}$ Nanin Sumiarmi, Pembelajaran Bahasa Arab,Holistik, Vol 15, No. 01, 2014

${ }^{4}$ Arin Baharsati, 2017. Pengembangan Media Pembelajaran Bahasa Arab Berbasis Multimedia Interaktif Menggunakan Adobe Flash Untuk Meningkatkan Minat Belajar Siswa Kelas VII Mts Negeri Wonokromo, (Yogyakarta: FTIK dan Keguruan, UIN Sunan Kalijaga) 


$$
\text { 1 - - أهداف تعليم المفردات }
$$

وهي الأهداف التي تركز على عمليات التذكر وإعادة إنتاج غبرة ماريفترض أن

المتعلم قد تعلمها, وهي كذالك الأهداف التي تتضمن حل بعض المهام العقلية الذهنية التي من أجلها يقرر المتعلم المشكلة الأسـاسية ثم يعيد ترتيب المادة أو ربطها بأفكار أو طرائق أو إجراءات سبق تعليمها, وتتراوها الأهداف المعرفية من استراجاع بسيط لمواد متعلمة إلى الطرق الأصلية الراقية لربط وتركيب الأفكار مواد جديدة. 5

2- أهداف تعليم المفردات بـ MTs Swasta Geudubang Aceh
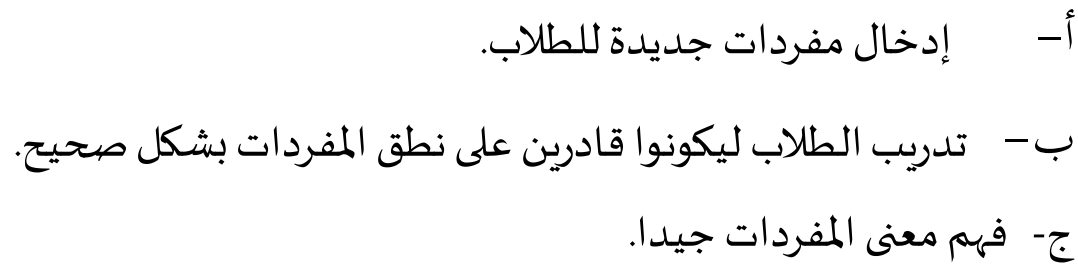

د- يتمكن الطلاب من التحدث المفردات بجيد واستخدامها في الحياة اليومية.

Adobe Flash 3

Adobe Flash

من ولايات المتحدة الأمريكية (peranti lunak)

هو incorporate ، هذا البرنامج جيدا جدا وشعبية بين الرسوم المتحركة.

البرنامج منها تقليدي عندما يريد شخص ما إنشاء العديد من تطبيقات الوسائط

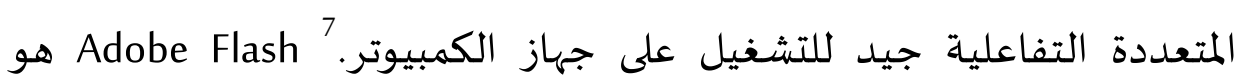

Adobe Flash ${ }^{8}$ softwere

5 بليغ ممدي إسماعيل ,استراتيجيات تلدربس اللغة العربية أطر نظرية وتطبيقات عملية, ( عمان - دار المناحج للنشر والتوزيع: 2013), ص: 45

${ }^{6}$ Elsa Novyarti, Dkk, Pengembangan Media Pembelajaran Menggunakan Adobe Flash Dan Autoplay Media Studio Dalam Pembelajaran Yang Berbasis Inquiry Pada Materi Garis dan Sudut Kelas VII SMP, ( Jambi : Edumatica Vol. 04 Nomor 02, Oktober 2014).

${ }^{7}$ Nunik Usyanti dan Susanti. 2015. Pengembangan Media Pembelajaran Akutansi Berbasis Multimedia Interaktif Pada Materi Rekonsiliasi Bank, jurnal pengembangan media pembelajaran multimedia interaktif Vol.03.

${ }^{8}$ Istia Alif Fanti, efektivitas media pembelajaran dengan adobe flash dalam model pembelajaran langsung untuk pencapaian unjuk kerja pembuatan pola dasar badan wanita di smk 6 yogyakarta, (uin Yogyakarta : 2012), hal.47 


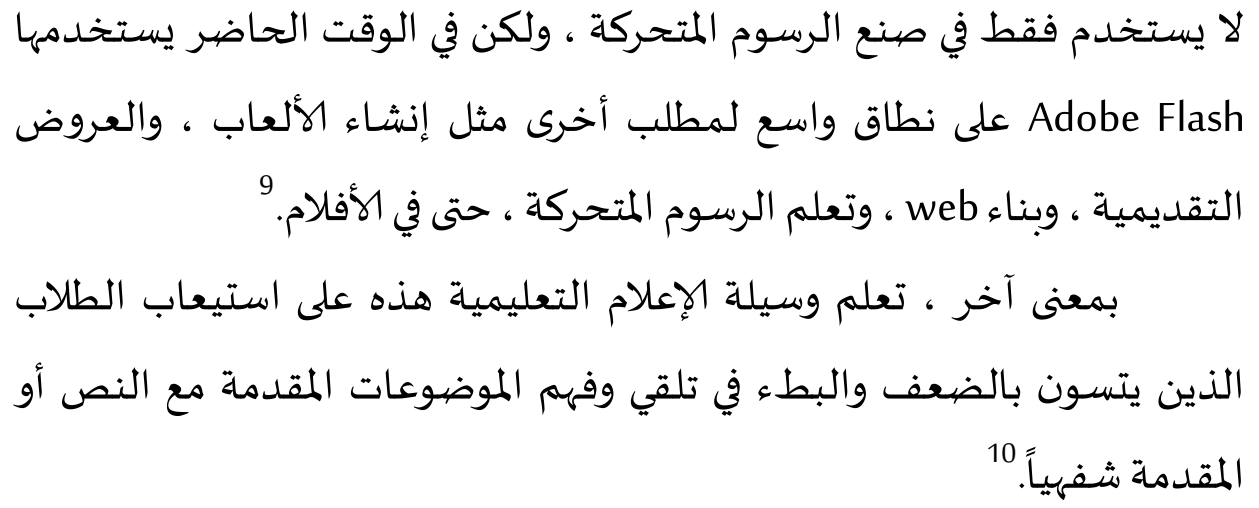

Adobe flash - خطوات في استحدام وسيلة

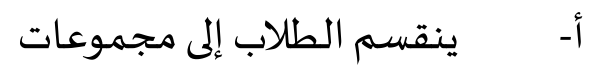

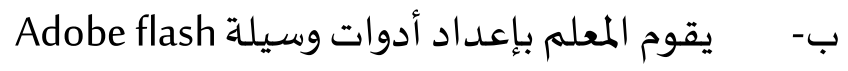

ج- يعرض المعلم المواد التي يمكن تعلمها باستحدام وسيلة Adobe

flash

$$
\begin{aligned}
& \text { د- يشرح المعلم للطلاب الدرس المطلوب مناقشته } \\
& \text { هـ- يطلب المعلم من الطلاب الانتباه والاهتمام بالدرس } \\
& \text { و - يطلب المعلم من الطلاب تسجيل ماتم عرضيه }
\end{aligned}
$$

ز- بعد انتهاء تسليم المواد ، يناقش المعلم والطلاب معًا المواد التي تم

تعلمها ، ثم يقولها مرارًا وتكرارً

\section{ج- منهج البحث}

تستخدم الباحثة في المدخل الكمي باستخدام بحث تجريبي. فالبحث التجريبي يعنى المنهج المحاولة لدراسـة تأثير من متغير خاص لمتغير اخر، من خلال الاختبار في

$$
\text { شروط الخاصية التي جعتها عمدا. }
$$

${ }^{9}$ Dedy Izhar, "Cara Cepat Belajar Adobe Flash". Dokumen Ilmu Komputer.Com (komunitas eLearning, 2012). h. 1.

${ }^{10}$ Oemar Hamalik, Media Pendidikan. (Jakarta: Citra Aditya Bakti, 1986). Hal. 43. 
وأما بحث تجريبي أحد المناهج العلمية تستعملها الباحثة الإختبار الفرض التي تضعها، خاصة عن رغبة في معرفة تأثير متغير مستقبل في متغير تابع، ومع إبعاد أو تحييد أثر المتغيرات المستقلة الأخرى التي قد تتدخل في العلاقة بين المتغيرين الرئسية.

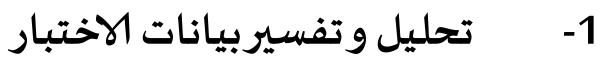

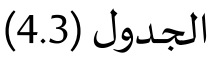

نتيجة الإختبار القبلى فى الفصل 2.2

\begin{tabular}{|c|c|c|c|c|c|}
\hline \multirow[t]{2}{*}{ التقدير } & \multirow{2}{*}{ مجموعة الدرجة } & \multicolumn{3}{|c|}{ الإختبار القبلى فى الترقية مفردات } & \multirow{2}{*}{ 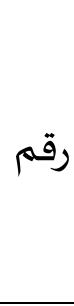 } \\
\hline & & $\begin{array}{c}1 \\
\text { (أجوبة 40) }\end{array}$ & $\begin{array}{c}2 \\
\text { (أجوبة 40) }\end{array}$ & $\begin{array}{c}3 \\
\text { (أجوبة 20) }\end{array}$ & \\
\hline راسب & 40 & 16 & 16 & 8 & 1 \\
\hline راسب & 52 & 16 & 24 & 12 & 2 \\
\hline راسب & 40 & 24 & 8 & 8 & 3 \\
\hline راسب & 48 & 24 & 16 & 8 & 4 \\
\hline راسب & 48 & 16 & 24 & 8 & 5 \\
\hline راسب & 52 & 24 & 16 & 12 & 6 \\
\hline راسب & 48 & 16 & 24 & 8 & 7 \\
\hline راسب & 40 & 16 & 16 & 8 & 8 \\
\hline راسب & 44 & 24 & 16 & 4 & 9 \\
\hline راسب & 52 & 24 & 16 & 12 & 10 \\
\hline راسب & 36 & 16 & 16 & 4 & 11 \\
\hline مقبول & 60 & 32 & 24 & 4 & 12 \\
\hline راسب & 48 & 16 & 24 & 8 & 13 \\
\hline مقبول & 56 & 24 & 24 & 8 & 14 \\
\hline
\end{tabular}




\begin{tabular}{|c|c|c|c|c|c|}
\hline راسب & 44 & 24 & 24 & 8 & 15 \\
\hline مقبول & 60 & 24 & 32 & 4 & 16 \\
\hline راسب & 44 & 24 & 16 & 4 & 17 \\
\hline مقبول & 60 & 24 & 24 & 12 & 18 \\
\hline راسب & 36 & 16 & 16 & 4 & 19 \\
\hline راسب & 44 & 24 & 16 & 4 & 20 \\
\hline راسب & 48 & 24 & 16 & 8 & 21 \\
\hline مقبول & 56 & 32 & 16 & 8 & 22 \\
\hline راسب & 52 & 24 & 24 & 4 & 23 \\
\hline راسب & 48 & 24 & 16 & 8 & 24 \\
\hline راسب & 40 & 24 & 8 & 8 & 25 \\
\hline راسب & 36 & 16 & 16 & 4 & 26 \\
\hline راسب & 40 & 16 & 16 & 8 & 27 \\
\hline راسب & 44 & 24 & 16 & 4 & 28 \\
\hline راسب & 40 & 16 & 16 & 8 & 29 \\
\hline راسب & 48 & 24 & 16 & 8 & 30 \\
\hline \multirow[t]{3}{*}{ مقبول } & 64 & 16 & 32 & 16 & 31 \\
\hline & 1426 & & & & المجموع \\
\hline & 46 & & & & الدرجدة \\
\hline
\end{tabular}

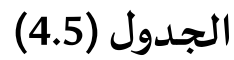

نتيجة الإختبار البعدى في الفصل 2.2

\begin{tabular}{|l|c|c|c|}
\hline & رقموعة & الإختبار القبلى فى الترقية مفردات & \\
\hline
\end{tabular}




\begin{tabular}{|c|c|c|c|c|c|}
\hline & & $\begin{array}{c}1 \\
\text { (أجوبة 40) }\end{array}$ & $\begin{array}{c}2 \\
\text { (أجوبة 40) }\end{array}$ & $\begin{array}{c}3 \\
\text { (أجوبة 20) }\end{array}$ & \\
\hline جيد جدا & 79 & 24 & 32 & 20 & 1 \\
\hline جيد & 80 & 24 & 40 & 16 & 2 \\
\hline جيد جـدا & 79 & 24 & 32 & 20 & 3 \\
\hline مقبول & 64 & 16 & 32 & 16 & 4 \\
\hline جيد جـدا & 79 & 24 & 32 & 20 & 5 \\
\hline جيد جدا & 84 & 24 & 40 & 20 & 6 \\
\hline جيد جـدا & 79 & 24 & 32 & 20 & 7 \\
\hline مقبول & 62 & 16 & 32 & 14 & 8 \\
\hline جيد جـدا & 79 & 16 & 32 & 20 & 9 \\
\hline مقبول & 64 & 16 & 32 & 16 & 10 \\
\hline جيد جدا & 84 & 24 & 40 & 20 & 11 \\
\hline جيد جـدا & 82 & 24 & 40 & 18 & 12 \\
\hline ممتاز & 92 & 32 & 40 & 20 & 13 \\
\hline مقبول & 64 & 24 & 24 & 16 & 14 \\
\hline جيد جدا & 82 & 24 & 40 & 18 & 15 \\
\hline جيد جدا & 78 & 24 & 40 & 14 & 16 \\
\hline جيد & 72 & 24 & 32 & 16 & 17 \\
\hline مقبول & 64 & 16 & 32 & 16 & 18 \\
\hline جيد جـدا & 80 & 24 & 40 & 16 & 19 \\
\hline ممتاز & 88 & 32 & 40 & 16 & 20 \\
\hline ممتاز & 96 & 36 & 40 & 20 & 21 \\
\hline جيد جدا & 79 & 24 & 40 & 20 & 22 \\
\hline مقبول & 64 & 24 & 24 & 16 & 23 \\
\hline مقبول & 64 & 24 & 24 & 16 & 24 \\
\hline مقبول & 64 & 24 & 24 & 16 & 25 \\
\hline جيد جـدا & 78 & 24 & 40 & 14 & 26 \\
\hline
\end{tabular}




\begin{tabular}{|c|c|c|c|c|c|}
\hline ممتاز & 92 & 32 & 40 & 20 & 27 \\
\hline جيد جدا & 79 & 24 & 32 & 20 & 28 \\
\hline جيد جـدا & 79 & 24 & 32 & 20 & 29 \\
\hline جيد & 72 & 24 & 32 & 16 & 30 \\
\hline \multirow[t]{3}{*}{ ممتاز } & 92 & 32 & 40 & 20 & 31 \\
\hline & 2394 & & & & المجموع \\
\hline & 77,22 & & & & معدل \\
\hline
\end{tabular}

\section{Tالإختبار}

اختلاف بين الاختبار القبلي والإختبار البعدى

\begin{tabular}{|c|c|c|}
\hline البعدى بيانات الإختبار T من الإختبار & بيانات الإختبار T من الإختبار القبلي & رقم \\
\hline 79 & 40 & 1 \\
\hline 80 & 52 & 2 \\
\hline 79 & 40 & 3 \\
\hline 64 & 48 & 4 \\
\hline 79 & 48 & 5 \\
\hline 84 & 52 & 6 \\
\hline 79 & 48 & 7 \\
\hline 62 & 40 & 8 \\
\hline 79 & 44 & 9 \\
\hline 64 & 52 & 10 \\
\hline 84 & 36 & 11 \\
\hline 82 & 60 & 12 \\
\hline 92 & 48 & 13 \\
\hline
\end{tabular}




\begin{tabular}{|c|c|c|}
\hline 64 & 56 & 14 \\
\hline 82 & 44 & 15 \\
\hline 78 & 60 & 16 \\
\hline 72 & 44 & 17 \\
\hline 64 & 60 & 18 \\
\hline 80 & 36 & 19 \\
\hline 88 & 44 & 20 \\
\hline 96 & 48 & 21 \\
\hline 79 & 56 & 22 \\
\hline 64 & 52 & 23 \\
\hline 64 & 48 & 24 \\
\hline 64 & 40 & 25 \\
\hline 78 & 36 & 26 \\
\hline 92 & 40 & 27 \\
\hline 79 & 44 & 28 \\
\hline 79 & 40 & 29 \\
\hline 72 & 48 & 30 \\
\hline 92 & 64 & 31 \\
\hline 22.77 & 46 & معدال \\
\hline
\end{tabular}

الإختبار T بستخدام الباحثة قيمة القبلي والبعدي كقيمة نهاية ليتم اختبارها, مع نتائج فيما يلي : 


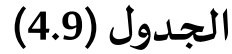

اختبار المعتادة الإختبار القبلى والإختبار البعدى فى الفصل 2.2

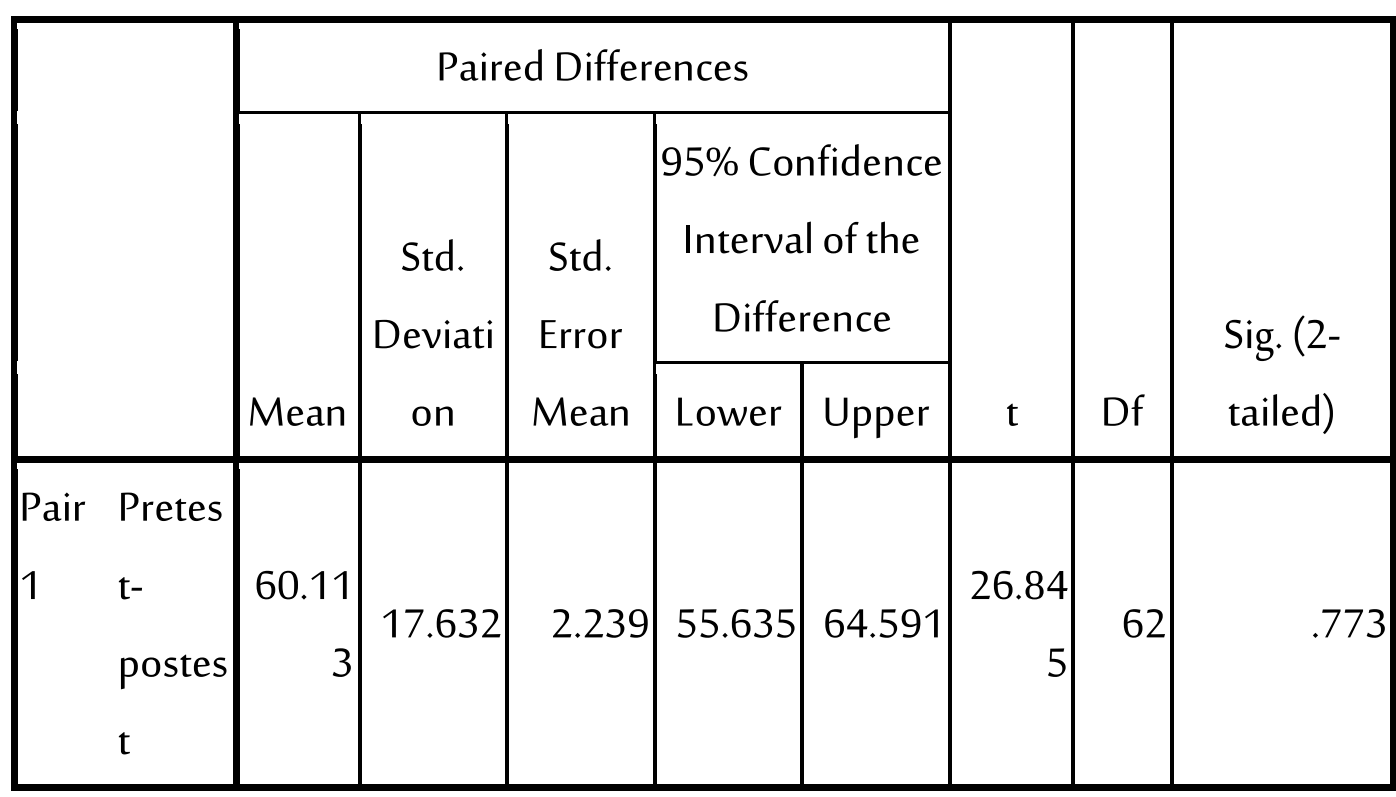

إن فرضية الإحصاء التى سيتم اختبارها فقال nana sudjana هي:

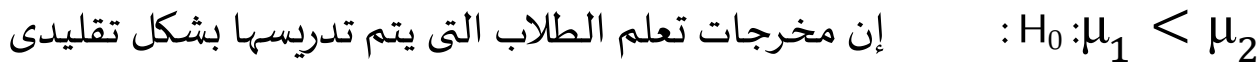

هلى أقل جودة من الطلاب الذين لا يتعلموم وسيلة Adobe Flash

MTs Swasta على قدرة تعليم المفردات في الصف الثانى

Geudubang Aceh

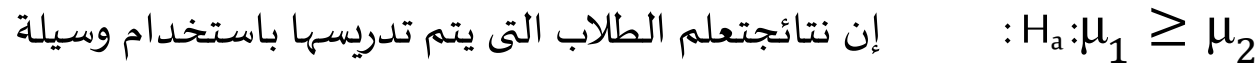

شيخلاث Adobe Flash هي أفضل أو مساوية لنتائج تعلم الطلاب

التى لا يتم تدرسها بشكل تقليدي في تعليم المفردات في الصف

الثانى MTs Swasta Geudubang Aceh.

$$
\begin{aligned}
& \text { إختبار معايير القرار 16pss-16: }
\end{aligned}
$$

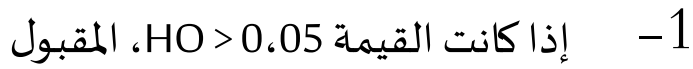




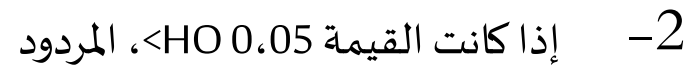

بناء على تفسير جدول المخرخات فوق Uji-T كانت تواجد درجة القبلى و البعدى هى

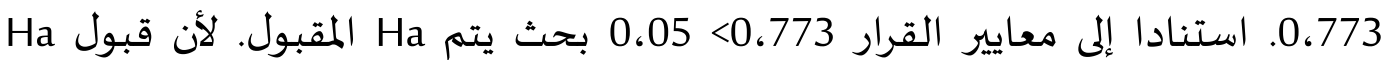
الاستنتاج هو النتائج تدريس الطلاب وسيلة Adobe Flashلترقية قدرة في المفردات الطلاب بـ MTs Swasta Geudubang Aceh جيد جدا فعلية.

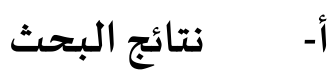

اعتمادا على النتائج حصلت عليها الباحثة في المجموعة التجريبية في الإختبار

$$
\text { القبلى والبعدى وجدت بينهما وهي : }
$$

ان استحدام وسيلة Adobe Flash في تعليم المفردات فعالية . وهذا الدليل كما في الجدوال 4.9 أن البيانات بأن نتيجية الطلبة في تعليم المفردات قد ارتقعت من قبل البحث وهي من " 1426 " أو بالمعدل 46 الى " 2394 " أو بالمعدل

$$
\text { ب- التوصيات البحث }
$$

بكتابة البحث يحسن بعض التوصيات التى نقدمها الباحثة الموجهاة إلى: 1- المدرس أن يدفع وإعطاء التوصيات أهمية تعليم اللغة العربية وتدريس

$$
\text { المفردات. }
$$

$$
\text { 2- المدرس يستخدم الطريقة المناسابة في المفردات. }
$$

3- أن يهتم المدرس باستخدام وسيلة Adobe Flash عند تعليم اللغة

$$
\text { العربية خصوصا في تعليم المفردات. }
$$

$$
\text { المراجع }
$$

بليغ حمدي إسماعيل. 2013. استراتيجيات تدرليس اللغة العببية أطر نظرية

$$
\text { وتطبيقات عملية. عمان دار المناحج للنشر والتوزيع }
$$

Baharsati, Arin . 2017. Pengembangan Media Pembelajaran Bahasa Arab Berbasis Multimedia Interaktif Menggunakan Adobe Flash Untuk 
Meningkatkan Minat Belajar Siswa Kelas VII Mts Negeri Wonokromo. Yogyakarta: FTIK dan Keguruan. UIN Sunan Kalijaga

Edi Komara, Moh. 2017. Penerapan Metode Pembelajaran Bahasa Arab. Journal Of Arabic And Litenature. Vol 1. No. 2

Fanti, Istia Alif. 2012. Efektivitas Media Pembelajaran Dengan Adobe Flash Dalam Model Pembelajaran Langsung Untuk Pencapaian Unjuk Kerja Pembuatan Pola Dasar Badan Wanita Di Smk 6 Yogyakarta. UIN Yogyakarta

Hamalik, Oemar. 1986. Media Pendidikan. Jakarta: Citra Aditya Bakti

Izhar, Dedy. 2012. Cara Cepat Belajar Adobe Flash. Dokumen Ilmu Komputer.Com komunitas eLearning

Novyarti, Elsa, Dkk. 2014. Pengembangan Media Pembelajaran Menggunakan Adobe Flash Dan Autoplay Media Studio Dalam Pembelajaran Yang Berbasis Inquiry Pada Materi Garis dan Sudut Kelas VII SMP. Jambi : Edumatica Vol. 04 Nomor 02 